\title{
Promoting Access to Children's Mental Health Care Services: Strategy and Policy Implications
}

\author{
Liranso G Selamu \\ PhD in Social Work, Mangalore University, Karnataka, India \\ Correspondence should be addressed to Liranso G. Selamu, liranso.2006@gmail.com
}

Received: April 26, 2021; Accepted: May 16, 2021; Published Date: May 25, 2021

\begin{abstract}
In recent years, children's mental illness has become a major problem; but little is known about the problems and the available literature does not address this issue properly. The present study was meant to examine the current mental health care situations to promote access to services for children in Addis Ababa. The data have been cautiously collected through multiple data collection tools such as semi-structured interviews, focus group discussions, and questionnaires. The data analysed and interpreted from wider perspectives. The study result indicated insufficient mental health policies, limited access to specialized treatment, shortage of human resources, lack of early treatment, and preventive programs/education. There is a need for the comprehensive strategies and mechanisms which take the relevant variables into account to strengthen specialized care and awareness among society via integrating the study evidence into practices. The authors described very significant implications for future actions such as conducting further empirical studies, regular discussions with responsible stakeholders, etc.
\end{abstract}

\section{KEYWORDS}

Mental Health Care, Services, Access, Strategies, Policies

\section{INTRODUCTION}

Globally, children's mental health service is the growing field of research, however, only a few researchers have begun to file the prevalence of children's mental illness issues, much less in regard to adult care [1]. This study aims to contribute to this growing area of research by exploring the existing children's mental health service delivery and to promote the service accesses in the study area. Children's mental health care can play a vital role in determining future social welfare, medical, costs, etc. for reducing the problems of the future society and socioeconomic burden of Government. Throughout this paper, there are several important areas where this study makes an original contribution to service delivery and promotion.

Furthermore, children's mental health services focus on diagnosis and care for existing mental disorders, or emerging illness and/or psychological problems. To develop systems that include the child, parents/guardians, organizations, and community members; and childfriendly services to prevent children's from severe mental illness. An early children's mental health service has a

Citation: Liranso G Selamu, Promoting Access to Children's Mental Health Care Services: Strategy and Policy Implications. Psychiatry 1(2): 29-38.

(C) 2021 The Authors. Published by TRIDHA Scholars. 
crucial role in child well-being, and where the children develop to use their full potential and healthy life. To say another way, positive mental health and well-being needs children's and caregivers/families involvement and working together to create a healthy community environment; and service sustainability [2].

A recent study by Jacqueline et al. [3] reported that there are high mental illness prevalence rates and big treatment gaps among children in sub-Saharan Africa. In an analysis of Jacqueline, the region has scarce trained manpower and economic resources and no clear pathway to access treatment, especially in-patient facilities and poor advocacy for children's mental health services. The comprehensive study of Melissa et al. [4] found that substantial levels of mental disorder exist among children in sub-Saharan Africa. It has been estimated that one in seven children have considerable psychiatric disorders in the region.

The growth of mental health care in most African countries is still in a weak and lack of human and financial resources and limited empirical evidence. Sub-Saharan Africa is a large region but characterized by low incomes, malnutrition, low life expectancy, and poorly staffed services, etc. An experienced mental health professional in sub-Saharan Africa is few in number and there are common beliefs that mental illness caused by evil-minded people and should be treated traditional and religious practices. In Africa, mental health issues frequently come very last on the list of priorities for policy-makers and have no mental health policies, programs or action plans [5].

Among the sub-Saharan countries, Ethiopia is one which the vast majority of people who suffer from mental illnesses remain untreated [6-10]. There are few clinical psychologists, trained social worker and few beds located in the mental hospital in Addis Ababa. Questions have been raised about the majority of mental health specialists' work in, the service is neglected in the rural areas of the country [11]. In Ethiopia, children have the highest (50\%) population rates of the total population [8]. However, the situations of mental health care for children are the most underprivileged health programs. Yet, the prevalence rate of children's mental disorders is $15 \%$; there is poor public awareness about the extent of mental disorders. Child mental disorders and their rights on the national economy and social harmony was the one major issue in early Menelik research concerned.

In Ethiopia, the burden of mental health is greater in particular for people with mental illness and for parents of severely ill children and adolescents. Debate continues about the best strategies for the management of mental health care services equally and effectively. It is necessary here to clarify exactly what is meant by service delivery and the mechanisms of the service promotion. An objective of this study was to investigate the mechanisms to improve access to mental health care services for children in Addis Ababa, Ethiopia.

\section{METHODS}

\section{Study Design and Sampling}

To accomplish the study purpose, descriptive design was used to describe, explain and interpret conditions and describes systematically and accurately the existing facts of child MHS from wider perspectives. The design allows researchers for gathering in-depth information by integrating various approaches for the wider picture and greater advantages in data collection and analysis [12-14]. There were a number of rationales for choosing a mixed method for this particular study. The researchers believed that a mixed method is the most suitable [15] to collects and analyze wider information and to discuss wider findings to improve the current mental health care services. The benefit of this approach is comprehensive and in-depth data collection tools and findings to assess 
the current mental health care services delivery in the study area.

The approach has the significance to evolve and increase the study issues step forward, by utilizing the strengths of both approaches and to gain an in-depth understanding of the service trend to dig deeper into the study's purpose. The design is the most useful approach for describing phenomena or events and allows for a multifaceted approach to data collection and analysis. The nature and advantages of the design directly compliment the envisaged aim of the study, which is to describe the access to mental health services for the orphan and vulnerable children as it occurs within the ongoing events of the present circumstances in the study area. The orphan and vulnerable children's serving organizations in Addis Ababa were included to collect rich data for the study purpose. With the reference of the child support organizations, all the available managers of the organizations, professional caregivers (psychologists, psychiatric nurses, psychiatrists, and social workers) and guardians of the children were included in the study. Convenience sampling was used in the selection of the caregiver participants based on their availability ranges and responsibilities in the organizations. MacLean et al. [16] showed that children raised in institutions had evidence of higher rates of mental disorders, and at great risk for developmental delays. An orphan and vulnerable child under 18 years of age who have lost parents from any causes have participated. Institutionalized children aged between 14 years - 18 years old and between 9 grade to 12 grade students were selected by applying the criterion sampling. In view of the fact that the participants understanding level and years of living in the organizations are significant enough to examine their experiences, and service practices and challenges. Through these associates and references of these participants, it was finally possible to accumulate relevant and broad data from wider perspectives.

\section{DATA COLLECTION AND ANALYSIS}

The researcher first contacted managers of the childserving organizations in the study area and granted permission from the managers to access the participants ethically. Then, psychologists and social workers of the organizations assisted the researcher to access the study participants and further discussed the aim of the study. The interviews and discussions were conducted in Amharic (the language spoken by the participants) and the official local language of the study area to avoid the interruption of discussions. The semi-structured interviews were carried out to dig out the useful stories behind the study participants' views, experiences, beliefs towards MHS and administration of the services. Kumar et al. [17] points out that it is the most appropriate tool to communicate participants ahead of asking insightful questions collect rich and in-depth data in person.

Besides, questionnaires are a well known tool within social science research for acquiring data based on participant social characteristics, agreement levels and their beliefs towards the study topic (Bulmer, 2004) [18]. The questionnaires were distributed to psychologists, psychiatric nurses, psychiatrists, and social workers to assess their knowledge and practices. Recently, focus group discussion has gained great recognition (Baxter and Jack, 2008) [19] amongst social scientists as a means of participatory data collection tool. Focus group discussions were conducted with the children to obtain detailed information about the existing situations and cross-check the data from the staff. The group members of the children discussed and reflected the service gaps and the existing situations of the organizations in depth.

To present the data in a manageable and understandable way, the questionnaire data was organized and entered into SPSS version 23 and analyzed in the form of frequency, percentages, interpreted and presented in manageable ways. Researchers Best \& Kahn [20] believed that 
descriptive method of analysis has great advantages to describe the basic features of the study data, provide simple summaries about the sample, the measures, and present quantitative descriptions in a manageable and easily understood form. By keeping in mind that one nature of research is described situations and events based on the characteristics of the respondents and study nature [21].

The interview and focus group discussions data were discussed in categorized and analyzed in the form of thematic analysis based on the study objective. The study data of FGDs and interviews conducted in the Amharic language were first translated into English and transcribed, classified and arranged. All the data were segmented into units of meaning to explore the concepts in-depth. Yolandi et al. [22] found that the trustworthiness of the analysis was enhanced by the appropriating reflexivity of the researcher's role during the study analysis. A transcription was read inductively several times and some participant's ideas and experience quotes were included in the text to understand a studied phenomenon further. Through using the descriptive nature of the organizations and targeted participants responses about the service accesses were described as follows in further in the result section.

Table 1: Demographic characteristics of the participants.

\begin{tabular}{|c|c|c|c|c|c|c|c|c|c|}
\hline \multirow[b]{2}{*}{ No } & \multirow[b]{2}{*}{ Items } & \multicolumn{2}{|c|}{ MH workers } & \multicolumn{2}{|c|}{ Managers } & \multicolumn{2}{|c|}{ Guardians } & \multicolumn{2}{|c|}{ Children } \\
\hline & & $\begin{array}{c}\mathbf{n} \\
32\end{array}$ & $\begin{array}{c}\% \\
100\end{array}$ & $\begin{array}{c}\mathbf{n} \\
18\end{array}$ & $\begin{array}{c}\% \\
100\end{array}$ & $\begin{array}{c}\mathbf{n} \\
42\end{array}$ & $\begin{array}{c}\% \\
100\end{array}$ & $\underset{117}{\mathbf{n}}$ & $\begin{array}{c}\% \\
100\end{array}$ \\
\hline \multirow{3}{*}{1.} & \multicolumn{9}{|c|}{ Sex of the Participants } \\
\hline & Male & 14 & 43.7 & 11 & 61.2 & 14 & 33.3 & 72 & 61.1 \\
\hline & Female & 18 & 56.3 & 7 & 38.8 & 28 & 66.7 & 45 & 38.9 \\
\hline \multirow{7}{*}{2.} & \multicolumn{9}{|c|}{ Age } \\
\hline & 13 years -15 years & - & - & - & - & - & - & 83 & 71.3 \\
\hline & 16 years -18 years & - & - & - & - & - & - & 34 & 28.7 \\
\hline & 21 years -30 years & 8 & 24.9 & 3 & 16.6 & 8 & 19 & - & - \\
\hline & 31 years -40 years & 11 & 34.4 & 10 & 50 & 20 & 47.7 & - & - \\
\hline & 41 years - 50 years & 9 & 28.1 & 2 & 11.2 & 8 & 19.1 & - & - \\
\hline & Above 51 years & 4 & 12.6 & 3 & 16.6 & 6 & 14.2 & - & - \\
\hline \multirow{5}{*}{3.} & \multicolumn{9}{|c|}{ Educational Level } \\
\hline & High School & - & - & - & - & 10 & 23.7 & 117 & 100 \\
\hline & Diploma and Certifications & 6 & 18.7 & 3 & 16.7 & 19 & 45.4 & - & - \\
\hline & Bachelor's Degree & 17 & 53.2 & 9 & 49.8 & 11 & 26.1 & - & - \\
\hline & Master's Degree \& Above & 9 & 28.1 & 6 & 33.5 & 2 & 4.8 & - & - \\
\hline \multirow{5}{*}{4.} & \multicolumn{9}{|c|}{ Religion } \\
\hline & Protestant & 15 & 46.8 & 9 & 49.9 & 20 & 47.7 & 54 & 45.9 \\
\hline & Orthodox & 12 & 37.4 & 7 & 38.9 & 17 & 40.4 & 39 & 33.1 \\
\hline & Muslim & 2 & 6.3 & 2 & 11.2 & 2 & 4.8 & 13 & 11.4 \\
\hline & Other & 3 & 9.5 & - & - & 3 & 7.1 & 11 & 9.6 \\
\hline
\end{tabular}

\section{ETHICAL CONSIDERATIONS}

Ethical approval was granted by the Research Ethics Committee at A Manuel Psychiatry Hospital in Addis Ababa, Ethiopia. All the study participants were given information about the study purpose, and the guardians' consent was used to collect data from the children and they gave consent to participate in the study. The study participants received information about their confidentiality and had the option to withdraw from the study at any time for any reason. 
http://www.tridhascholars.org | December -2021

\section{RESULTS AND DISCUSSION}

The objective of the study was to explore the mechanisms to improve access to mental health care services for orphans and vulnerable children in Addis Ababa. The conceptualization of the study was based on the World

\section{POLICIES AND STRATEGIES TO IMPROVE} ACCESS TO CHILD MENTAL HEALTH

\section{CARE SERVICES}

In the above Table 1, most of the study, participants were forward important ways for overcoming the barriers of children's mental health problems which consist of policy formulation to enforce legislation/Law to expand mental health care and rehabilitation centers in the study area. Disseminating mental health information and the provision of mental health care services also recommended to easily reaching the community members and to reduce children's drug abuse, chewing chats, drinking alcohol, etc.

In addition, the respondents also indicated the clear way in which the caregivers and other staffs need this further information and incentives to improve the required provision of mental health care services for the children. The majority of them believe that there is a need to reassess the current mental health policy of the county being implemented by involving mental health specialists, researchers, higher Government officials and stakeholders in preparing new policy and strategies. They also described that access to free services for the children and availability of medications also promotes a modern mental health care service. Furthermore, the study participants revealed that the community members and trained staff would promote mental health service accesses.

However, the majority of the community members in the county preferred religious healing practices and traditional medicines as the best ways to cure mental health problems and easily accessible among the community. In the causes
Health Organization [23], MHS domains integrated with the study objective. It mainly included the clear way in which the caregivers and other staff suggested ways to improve the children's mental health care services. The study results were described as follows.

Ethiopian community members', of mental illness related to religious and cultural beliefs, and most people believed that its treatment also linked to religious healing practices and traditional medicines. A broad visible basis of mental illness within Ethiopian society is incredible related to an evil spirit, drug or substance abuse, stress, and physical illness. Additionally, Ethiopia has an extended history of traditional medicines and cultural health beliefs, and more dependent on religious rituals to cure.

The Guardian respondents were recommended ways they would prefer to have mental health information from Medias, newspapers, the use of posters/pamphlets were as the means to be helpful to get some knowledge and basic information to help the children. Few guardians conducting community coffee ceremonies and drama may be useful to improve the children interact with other community members to minimize mental health problems related to stigma and discrimination $[6,10]$. It is therefore highly necessary to bring awareness among people to seek professional mental health services to better address the needs of the children, supplement early screening efforts with mental health education as well as expand comprehensive mental health treatment in the study site.

The majority of the guardians were responded that the preferred sources of receiving and sharing mental health information was community mobilization as the genuine means specially to work with the community attitude towards the mental disorders of the children. The study participants were indicated social mobilization as the best way to share mental health education and to disseminate the relevant information and suggested empirical research 
on children's mental illness and service needs. Especially, there is research need on current treatment practices, cultural beliefs, and prevalence rate and mental illness types are demanding research area to understand the real and current situation scientifically to realize its improvements and challenges in the study area.

In addition, social workers and community members would have a preference for the specific community mental health information; by using different methods like Media broadcast, involving community leaders, etc. Likewise, the caregivers indicated that providing effective mental health awareness and distribution of the information needs media communication to a far-reaching and convenient tool to get to the most community members to incorporate in any plan of children's mental health care services. On the other vein, the FGDs participants have specified some Medias such as ERK Mead and Fana broadcasting to create awareness and enlighten society.

The FGDs participants have a strong desire to attend professional mental health services. One of the FGDs participants expressed her wish as follows: "I wish if all of my family members visit mental health professionals especially the psychiatrist I met as their therapist for her family mental health problems as well (FGD. 11). This indicates the informant was acknowledging the need for psychiatric services for their psychosocial problems and even for their families and community members. And her expression indicated that the community is not aware of the enormous mental health burden and professional mental care and support, but it shows that nothing is being done at the community level to enhance professional mental health treatment.

One of the managers further, express such desires for mental health services to conduct community mobilization within the organization, however, the professional psychiatric services are not considered as relevant service since the community members more preferred the religious practices as the best solution to cure of mental health problems. For instance, he said:

"As to me, professional psychiatric treatment is important for the children's wellbeing, however, our community are those that don't aware of the significance of mental health care services that much. The donors' support also focused on basic needs (food, clothes, housing, formal education, and training)" (Mg. 09).

The above quote implies that the manager personally would accept mental health care services, however, the donors and community members don't aware of the benefits of professional treatment/services. Assumed that, some staff would accept psychiatric services, but the level of acceptance may get support if the services are accessible in the study area (Table 1). The manager's beliefs towards children's mental health service are key determinants to use and expand or reject professional services. Whether the managers' belief could influence the acceptance level of the services or else, their beliefs towards the service would affect the expansion of the service in the study area.

The study participants also indicated the ways to improve the services by building the capacity of the caregivers, improving the overall mental health care systems, overcoming the identified hindrances and conducting empirical studies. Especially their responses focused more on the need for capacity building through different training; funding and facilities for child psychiatry and mental health education was indicated repeatedly.

The interview informants also suggested some other ways of reducing stigma and discrimination linked with children's mental health problems from the community [6$8,10]$. Furthermore, most of them believed that community mobilization and campaign, radio and TV programs, 
religious leaders' involvement, public ceremonies, and education are the main possibilities for stigma reduction. Besides, changing community beliefs towards the mentally ill individuals, policy formulation against stigma and discrimination and conducting regular conferences with community members were suggested. The following quote from one of the managers' supported the above responses: She indicated that:

"You are the first person to come here to conduct research and talk about children's mental health. As to me, creating awareness is the first thing to promote mental health care services in our community. When people discern about the causes of mental health problems and professional treatment, then the services will be more effective. To this end, mental health professionals are responsible to give lectures in different community settings such in church, schools, community meetings, etc. when these mechanisms put into practice, effective mental health services will be delivered to the children” (Mg. 02).

Furthermore, she added:

"If the concerned bodies first enlighten the community, then it is easy to promote the service activities widely. You see, if the community members are aware, they will participate and receive the professional services and even they may advertise the services for other uneducated community members. I think mental health professionals, researchers, medias, and policymakers have a lot to do" (Mg. 02).

It has been indicated by the study participants that cultural beliefs and lack of training affect the services needs stakeholders' attention as well. As suggested in the above section, caregivers need training needs and acknowledged inadequate services and skill gaps to be able to handle the mystery of children's mental health problems. Also, there was poor knowledge demonstrated to the diagnosis of the specific mental illness and to provide the service accordingly. Therefore, most of the study participants suggested their best ways by which the caregivers' participant in regular staff training, workshops, and seminars on mental health care services can improve the services access, effectiveness and awareness in the study area.

On the other hand, one of the managers illustrated his concern as follows:

"I think, first of all, we should start to educate the children and the guardians about mental illness signs and symptoms. Besides, it is better for the caregivers use short psychological tools that are uncomplicated to assess the mental health level of the children; they can manage the tool to their guardians as well. There are specific instruments using by other countries to determine the occurrence of mental health problems and providing effective psychiatric services" (Mg. 13).

He repeated that:

"There are psychological tools such as mental health symptom checklists, quizzes, self-assessment, and screening tools to assess different mental health problems. I think these tools are using by European and Western countries. If we get the training on these tools and how to prepare the tests based on Ethiopian culture, administering and interpreting the situations of the children may improve the service provision from symptom identification to further treatment based on the specific problems of the children (Mg.13).

On the other hand, mental health workers said that such training is not the best measure but a service method. It requires having mental health guidelines and strategies to conduct follow up to see children's behavioral changes and caregivers skill gaps, but we have not child psychiatry policy and strategies in the country. They yet said that 
some caregivers have their own style of care delivery and have high-quality networking and referral. There is an effort to expand service access by working with some community members and religious organizations. Some child support organizations were creating awareness on mental health problems and its bad effects on the community members at the same time thus, reducing stigma towards the children and the service load on the caregivers.

The majority of the study participants were suggested that there should be mental health professionals in each organization to follow the whole service cycle to incorporate mental health services like other services (Table 1). A professional and community involvement was suggested as key essentials to start, sustain and advance mental health care services in the area. Furthermore, the services improvement needs formulating comprehensive service guidelines, conducting short term training, regular seminars, and workshops, the inclusion of community members and government officials and networking with stakeholders were suggested repeatedly by the study participants.

The all-inclusive strategy includes interventions that strengthen the skills of children and their guardians; and promoting mental health education through school-based programs, scientific research, and community programs. FGDs expressed "Truly, no attempt was made for our mental health care. All the stakeholders and the local government should hear our voice and give attention as a citizen of the country and work in collaboration to expand the service access (FGDs, 14)

To create awareness about the children's mental health services, community mental health providers work with the local schools and Medias and prepare brochures to reach the community members and other stakeholders' partnership. A variety of strategies are utilized to ensure best practices and to provide services in collaboration. Interdisciplinary team meetings among mental health staffs from (organizations, schools, and public hospitals) were suggested to work on life skills programs and child development programs and to strengthen antidiscrimination laws and campaigns. Finally, distributing mental health resources among schools, like printed material and brochures to increase awareness about mental health problems and its treatment ways among the children.

\section{CONCLUSION}

The study was to explore the mechanisms to improve access to mental health care services for orphans and vulnerable children in Addis Ababa. The local government expenses in children's mental health care are smaller and unreasonable in comparison with investments in older age groups and spending on other health services. The option of finding suitable child mental health care in the public system is remote and is expensive and inaccessible in the country. Thus, the study participants were forward important ways for overcoming the barriers of children's mental health problems which consist of policy formulation to enforce legislation/law to expand mental health care and rehabilitation centers in the study area. Most of the study participants believed that community mobilization and campaign, radio and TV programs, religious leaders' involvement, public ceremonies, and education are the main possibilities to promote the services. National health policy changes and new strategies are compulsory to reducing the burden of mental illnesses and addressing the needs of children.

\section{IMPLICATIONS}

In response to children's mental health service access, working in the public health system, empower healthcare workers, particularly psychologists/ child psychiatrists. There is a lack of information/awareness about mental disorders and fear regarding treatment. To address these 
problems, disseminating mental health information and formulating comprehensive service guidelines, conduct regular training, seminars and workshops, the inclusion of community members, government officials, and networking. An empirical study focused on child mental health services must be conducted to create a comprehensive understanding of the various issues and the type of care and evidence for the effectiveness of care. In general, align the children's mental health service with the local government/policymakers, Ministry of Women, Children, Ministry of Health, researchers, nongovernmental and community-based organizations, etc.

\section{AUTHORS' CONTRIBUTION}

The author was contributed to a lot of international research journals, and books for the international communities. This journal may serve as a strong scientific as a springboard to improve access to child mental health care services and begin to shed light on the contemporary relevance in mental health with a special focused on orphan and vulnerable children to move science forward.

\section{REFERENCES}

1. Liranso G, Mohan S (2018) Barriers in accessing children's mental health care services in Ethiopia. Primary Health Care: Open Access 8(1): 288.

2. Children's Mental Health Ontario Association (2002) Children's mental health services for children zero to six: Review of the literature and practice guide. Ontario 40 St. Clair Ave., East Toronto.

3. Owen JP, Baig B, Abbo C, et al. (2016) Child and adolescent mental health in sub-Saharan Africa: A perspective from clinicians and researchers. British Journal of Psychiatry International 13(2): 45-47.

4. Cortina MA, Sodha A, Fazel M, et al. (2012) Prevalence of child mental health problems in Sub-Saharan Africa. A systematic review. Archives of Pediatrics and Adolescent Medicine 166(3): 276-281.

5. Alem A (2000) Human rights and psychiatric care in Africa with particular reference to the Ethiopian situation. Acta Psychiatrica Scandinavica 399: 93-96.

6. Hailemariam KW (2015) Perceived causes of mental illness and treatment seeking behaviors among people with mental health problems in Gebremenfes Kidus Holy Water Site. American Journal of Applied Psychology 3(2): 34-42.

7. Desalegn A (2016) Conceptualization of mental illness and treatment practice among traditional healers in Gondar city. Master thesis: Addis Ababa University press, Addis Ababa, Ethiopia.

8. Desta M, Deyessa N, Fish I, et al. (2017) Empowering preschool teachers to identify mental health problems: A tasksharing intervention in Ethiopia. International Mind, Brain, and Education Society and Wiley Periodicals 11(1): 32-42.

9. Ayano G (2016) Primary mental health care services in Ethiopia: Experiences, opportunities and challenges from East African Country. Journal of Neuropsychopharmacology \& Mental Health 1(4).

10. Reta Y, Tesfaye M, Girma E, et al. (2016) Public stigma against people with mental illness in Jimma Town, Southwest Ethiopia. PLoS ONE 11(11): e0163103.

11. Alem A, Lars J, Charlotte H (2008) Community-based mental health care in Africa: Mental health workers' views. World Psychiatry 7(1): 54-57.

12. Creswell JW (2015) A concise introduction to mixed methods research. Thousand Oaks, CA: Sage publications.

13. Creswell JW, Plano Clark VL (2011) Designing and conducting mixed methods research (2 ${ }^{\text {nd }}$ Edn.). Thousand Oaks, CA: Sage publications. 
http://www.tridhascholars.org | December -2021

14. Ivankova NV, Kawamura Y (2010) Emerging trends in the utilization of integrated designs in the social, behavioral, and health sciences. Sage Handbook of Mixed Methods in Social and Behavioral Research $2^{\text {nd }}$ (Edn.). Thousand Oaks, CA: Sage Publications 581-611.

15. Creswell JW (2009) Research design: Qualitative, quantitative, and mixed methods approach. Thousand Oaks, CA: Sage Publications.

16. MacLean K (2003) The impact of institutionalization on child development. Development and Psychopathology 15(4): 853-884.

17. Kumar R (2005) Research methodology - A step by step guide for beginners $2^{\text {nd }}$ (Edn.). London: SAGE Publications Ltd. 18. Bulmer M (2004) Questionnaires $1^{\text {st }}$ (Edn.). Sage Benchmarks in Social Science Research Methods, edited by: Bulmer, M., Sage Publications, London.

19. Baxter P, Jack S (2008) Qualitative case study methodology: Study design and implementation for novice researchers. The Qualitative Report 13(4): 544-559

20. Best J, Kahn J (2003) Research in education $9^{\text {th }}$ (Edn.). Prentice-Hall of India Private limited, New Delhi.

21. Rubin A, Babbie E (2005) Research Methods for Social Work $6^{\text {th }}$ (Edn.). Belmont, CA: Thomson Brooks Cole.

22. Yolandi S (2003) Primary caregivers' experiences of rising children with autism: A phenomenological perspective. Rhodes University, Graham's Town.

23. World Health Organization (2001) Atlas: Country profile of mental health resources. Geneva, Switzerland. 